\title{
ANGUSTIA ANTE LA NADA
}

\author{
Héctor Sevilla Godinez \\ Universidad de Guadalajara \\ hector.sevilla@academicos.udg.mx
}

\begin{abstract}
RESUMEN / ABSTRACT
El artículo contiene un conjunto de reflexiones en torno al cambio que corresponde al hombre cuando es capaz de reconocerse ante el abismo de la nada. Obviamente, este encuentro con la nada genera angustia, la cual puede ser un obstáculo para la liberación. De tal modo, la intención de este texto es presentar a la angustia como una consecuencia de la incertidumbre, la cual es propiciada por la necesidad humana de tener todo bajo control; en ese sentido, superar la angustia ante la nada permitirá que el hombre la reconozca como una pauta y posibilidad de liberarse de las estructuras que asfixian y condicionan al individuo. Bajo esa óptica, el artículo termina refiriendo el carácter ineludible del cambio y la importancia de reconocer, como seres humanos del mundo contemporáneo, la nada implícita en el ser.
\end{abstract}

PALABRAS ClaVE: angustia, nada, liberación, incertidumbre, cambio.

\section{ANGUISH IN THE FACE OF NOTHING}

The article contains a set of reflections regarding the change that corresponds to man when he is able to recognize himself before the abysm of nothingness. Obviously, this encounter with nothingness generates anguish, which can be an obstacle for liberation. In such a manner, the intention of this text is to present anguish as a consequence of uncertainty, which is propitiated by the human need to have everything under control; in that sense, overcoming the anguish before nothingness will allow man to recognize it as a guideline and possibility of liberating himself from the structures that suffocate and condition the individual. Under that optic, the article ends referring to the characteristic of change and the importance of recognizing, as human beings of the contemporary world, the nothingness implicit in the being.

KEYWORDS: Anguish, Nothingness, Liberation, Uncertainty, Change.

\section{Exordio}

\footnotetext{
$\overline{R M}$

El artículo se ocupa en un primer momento del modo en que la angustia puede ser confundida con la experiencia de la nada, mostrando que tal angustia es, más bien, propiciada por la incertidumbre que provoca la experiencia nihilista. Posteriormente, se matiza una propuesta alterna de liberación centrada en la nada; finalmente, se alude, en el último apartado de este artículo, al inevitable proceso del cambio y la relación de este con la presencia de la nada.
} 


\section{La angustia como evidencia de la incertidumbre}

En realidad no es que el ser esté encima de la nada, como si fuera posible una posición entre ambas cosas, sino que el ser es la consecuencia de la nada en un sentido amplio. Cuando el ser emerge de la nada, no es por el ser mismo o por la nada, en cuanto que realicen una función para que eso suceda, sino que el humano tiene un ser que se ha hecho conciencia de ser.

Por tanto, no se trata de que el ser sea más notable que la nada, sino que es lo único que se puede ver. La nada permanece no visible, escondida tras el telón mientras el ser ha salido a dar la función. Somos conciencia de lo que acontece en el mundo de lo fenoménico que está al alcance. No somos conciencia plena de la nada porque, si así fuese, seríamos la nada. Somos entes en relación constante con su no-ser, pero no con la nada absoluta. Al no ser conscientes de la nada, lo que nos queda es intuirla por medio de lo que es.

Usualmente se ha creído que una de las experiencias que permiten intuir a la nada es cuando se vive la angustia; para Sartre (2006, p. 59) esta angustia es "la nada que se muestra como fenómeno". Por el contrario, cabría pensar que la angustia no muestra en ella a la nada, sino que nuestra idea de la nada sostiene a la angustia debido a que no hemos captado a la nada realmente, sino que la inferimos o la entendemos como algo amenazante que está detrás de aquello que vivimos; es por eso que tememos a la nada y esta nos angustia. No puede sostenerse que la angustia es la vivencia privilegiada en que la nada se hace fenómeno, sino que la angustia está más relacionada con la incertidumbre y con la falta de claridad de algunos acontecimientos a los que nos enfrentamos.

La incertidumbre se genera como la conciencia de no tener una respuesta clara. En este caso se trata de una conciencia de no-saber, la cual se constituye como conocimiento de la ignorancia. En ese sentido, de acuerdo con Cioran (2009, p. 25), no hay forma de conceder que el hecho de sufrir se realiza en forma independiente a la subjetividad, debido a que "el sufrimiento no es objetivamente evaluable, pues no se mide por signos exteriores o trastornos precisos del organismo, sino por la manera que tiene la conciencia de reflejarlo y de sentirlo".

En ese sentido, cuando uno se reconoce no sabio solo podría angustiarse si supone que debe ser sabio, tal como reconocerse soberbio solo podría ser preocupante en caso de creer que no debiera ser así, o que es deber evitarlo a toda costa. No tendría que haber angustia en la incertidumbre a menos que supongamos que este es un mundo de certidumbres y que tengamos, por ello, la expectativa de la no-incertidumbre. Es decir, la angustia solo será posible, en este caso, si se ha tenido como deseo íntimo saberlo todo o tener claridad siempre. No hay angustia posible sin la antecedente connotación de que algo debe ser de un modo específico. En otras palabras, la angustia es producto del afán por seguir una visión univoca, tal como restringirse a un enfoque moral unilateral.

De tal modo, no hay angustia posible que no esté precedida de la expectativa. Por ello, el reconocimiento de la nada en uno mismo sería una contraparte de la angustia que se experimenta por esperar certidumbres. Siendo así, la angustia no es el fenómeno por el que la nada se muestra, sino más bien el fenómeno que muestra nuestro temor 
y resistencia a la nada. Solamente habrá vivencia de la angustia por no encontrar respuestas si antecede la expectativa de encontrarlas o persiste el juicio moral de que la incertidumbre supone una falta o falla de nuestra parte. Generamos las expectativas de manera multifactorial, puesto que la expectativa no es la esencia del hombre sino que le llega al hombre, la asume o absorbe de un entorno particular.

La manera particular en la que cada individuo se angustia está en franca relación con su manera de negar la nada en sí mismo y, por tanto, en absoluta proporción a lo que aprendió que debía ser. Se infiere que entre los estorbos más claros para el logro del encuentro con la nada está la moralización. Tal concepto puede entenderse como la categorización de la conducta humana según un esquema determinado de maldad o bondad, lo cual está siempre en relación con un sistema ideológico específico al que cada persona se adhiere. Este sistema delimita la vida humana al grado de que la estructura no permite la conciencia de la propia vacuidad. Tras las estructuras, rompiéndolas, está la aceptación de la nada.

Establecer distinciones entre nuestra manera de percibir el ser o la nada, buscando separar ambos constitutivos como si fueses antagónicos, representa una de las formas en que nos esclavizamos a las estructuras, comenzando por los referentes cognitivos que nos orillan a anhelar el encuentro con el ser y a temer el roce con la nada, manteniendo así un desencuentro. Mucho tiene que ver la estructura lingüística desde la cual nos explicamos el mundo. En tal estructura, por ejemplo, encontramos distintos matices de la palabra libertad. Ahora mismo conviene dedicar un espacio a la posibilidad de la liberación por medio de la nada, para lo cual resulta de fundamental importancia lograr desentenderse de la supuesta necesidad de ser libres.

\section{La nada como pauta y posibilidad de la liberación}

Si tras la estructura del yo está la nada pura, también estaría ahí la libertad. La primera de las estructuras es la vida, así como el sistema de la vida al cual se adapta el yo. Ahora bien, si la nula estructuración implica la muerte, entonces la libertad, como experiencia vivida, solo es posible debido a la estructura. No hay libertad, como anhelo o como posesión, sin la existencia de la cárcel estructurante. En otras palabras, es necesario ser prisionero para ser libre, puesto que la estructura es el sostén de la libertad.

Seguido de esto es captable el error sartreano que le condujo a pensar la libertad como un hecho ontológico. Lo anterior se explica con cinco argumentos: 1) el ser ontológico no tiene por sí mismo una estructura que pueda ser perceptible; 2) debido a lo anterior, la estructuración de la vida humana no responde a su entidad ontológica, sino precisamente a su condición de estar en relación con el mundo; 3) la libertad resulta emergente de la estructura, no hay libertad sin ella; 4) si la estructura no es ontológica, tampoco puede serlo la libertad; 5) ante una libertad no ontológica solo queda la libertad en la estructura, de modo que buscar la libertad partiendo de la desestructuración total es un equívoco que la imposibilita.

Por tanto, si la libertad es posible en función de la estructura, la cual puede ser opresora, solo queda una de dos opciones: la libertad y la prisión son lo mismo o la 
libertad es una estructura que igualmente aprisiona. Es decir, estamos encarcelados por la libertad, lo cual es distinto al sentido que Sartre da al término "condenado a la libertad". Sartre entendía que nuestra condena a la libertad consiste en la obligación de decidir. Pero, desde la perspectiva que aquí se presenta, la libertad no está relacionada con la necesidad de decidir sino solamente con la necesidad de ser. El hombre se concibe libre en cuanto que está encarcelado en la realidad estructurada que le envuelve, permaneciendo tan oprimido que su nada esencial no es percibida. Las decisiones que el hombre o la mujer eligen son producto de su propia estructura, de modo que el solo hecho de decidir nos les hace libres; por el contrario, decidir es jugar con la estructura e intentar ser alguien dentro de lo que en realidad no es.

Decidir es suponer que existe una opción correcta y esto implica la expectativa de que así sea, pero como no hay certidumbre sobre la decisión ideal llega la angustia que, según Sartre, sería la prueba de la libertad. El esquema aquí propuesto difiere en esto: la libertad es, única y precisamente, una idea que conduce a un anhelo forjado a partir de las estructuras opresoras ineludibles desde las cuales somos. Liberarse de la libertad requiere entender con profundidad que no puede hablarse de la libertad sin la estructuración, a pesar de que esta suele ser vista como su impedimento.

De que nadie puede desligarme de la estructura (ahora mismo se hace uso de ella para hablar de esto), puede derivarse de que la consecuencia de vivir es la ausencia de libertad en el sentido absoluto; esto último, sin embargo, implica una plena posibilidad de liberación desde la nada, precisamente por la imposibilidad de la libertad sin la estructura. En resumen: el ser se muestra en la estructura y lo que captamos es el ser y no la nada, pero la nada se infiere por lo que vemos del ser. La potencia del ser es la nada y la nada es en acto siempre, de modo que ambos son una unidad dialéctica. Anhelamos la libertad que siempre permanece en potencia y su único modo de ser es no siendo, por lo cual la liberación de la libertad es asumir su imposibilidad como realización, desesperanzándose de ella para no someterse a la esclavitud de su deseo.

Es comprensible la suposición de que la libertad se observa en los fenómenos que implican actos que conducen a la superación de la estructura, pero no es posible actuar sin la estructura misma, motivo por el cual la libertad está aprisionada en la estructura que la forja. El yo se encarcela al deseo de libertad y a la suposición de su obtención, pero solo sigue el juego estructural. La libertad humana está ligada a las estructuras que la limitan. El yo, al ser una estructura, es necesario para la elaboración ilusa de la libertad, pero solo en la nada (la estructura que desestructura) es posible la libertad absoluta. Se asume la liberación de la libertad al reconocer que no hay estructuras que permiten la libertad mínima de lo humano.

Tal liberación de la libertad consiste en asumir la nada desestructurada que no es captable. De tal modo, no se es libre al ser, mucho menos al actuar, pues tales libertades aprisionan hasta que muera nuestro ser. Morir al ser es reconocer la nada, asumir que nos posee; no negarle es hacerse nada de una vez por todas. Cada ser necesita de la nada que lo hace ser. Los límites son la libertad, no es posible una libertad derivada del derrumbe de los límites, sino que nuestra conceptualización de la libertad y la rigidez ante ella son el límite. 
La libertad es contingente a los límites, no al hecho de tomar una opción o a la decisión. Incluso sin haber tomado una decisión, la libertad tiene límites. La libertad no consiste en construirse o hacerse (ya somos), sino solo en ser, entendiendo que ese ser se deposita en la nada y no en lo que creemos que somos. Se trata entonces de una nada ontológica, no una nada anonadadora.

La nada es lo único que no puede ser pensado con un no-ser, pues su manera de ser es distinta a la que provoca la existencia del no-ser. Ella misma es su ser y no-ser, de tal modo que si llegase el punto en que no sea seguiría siendo la nada; su no-ser es al mismo tiempo que es. La nada es un no-ser constituido. Sartre (2006, p. 65) opina que: "ni siquiera puede decirse que la nada sea excluyente del ser: carece de toda relación con él". En su libro El ser y la Nada, afirma que "falta averiguar en qué delicada y exquisita región del Ser encontraremos ese Ser que es su propia Nada" (2006, p. 66). Tal región intuida por Sartre pertenece al ámbito de lo humanamente incognoscible, el cual es inferido de modo contrario a como usualmente suponemos conocer. La parte del presente en que éste deja de serlo es la parte de la nada.

Siendo así, el humano solo es consciente de la nada de manera intuitiva; si se tuviese la capacidad de forjar o crear a la nada, ésta dependería del ejercicio humano y no sería anterior al hombre mismo.

Este conjunto de relaciones que configuran la manera específica de nuestro ser en el mundo es lo que forja la estructura. No solo estamos en relación con otros, sino que también estamos vinculados con el lenguaje, la cultura, las costumbres, los modos, ritos, creencias, ideas, fantasías, demostraciones artísticas, criterios, entendimientos, modas y estereotipos que implican una vida social y que, por tanto, suponen la vida en relación con otros. Tales relaciones también se estructuran desde "campos específicos" (Bourdieu 2005) a los cuales la persona se conecta para encontrar un sentido que, finalmente, es dado por la misma estructura.

De tal modo, la manera de comprender la libertad se especifica según sea el campo estructural en que una persona se desempeña; debido a que la estructura externa a la que el hombre se adecúa no es su propia entidad, no es su ser, podemos distinguir al ser humano de la estructura si focalizamos su no igualdad con ella, pero no en función de la independencia hacia tal, puesto que no hay humano sin estructura. Por ello, la vida social del hombre vuelve inevitable la estructura. Para Sartre (2006, p. 68), la cuestión se soluciona de otro modo: "la libertad humana precede a la esencia del hombre y la hace posible; la esencia del ser humano está en suspenso en su libertad"; de tal manera, Sartre no distingue la libertad de la entidad humana y no deja dudas sobre su postura cuando afirma que "no hay diferencia entre el ser del hombre y su ser libre" (Sartre 2006, p. 68). No obstante, es complejo afirmar con tal serenidad que la libertad sea indistinguible del ser o que se tenga der por sí solo por ser. En el planteamiento sartreano no se observa la contingencia de la libertad hacia la estructura misma, cuestión que es inevitable.

El hombre no es la estructura social, sino que se estructura él mismo en ella. Si la libertad depende de una estructura que no es la esencia del hombre, no es admisible que la libertad sea la esencia humana. Tal esencia está en relación directa con la nada, 
está indefinida, es una nada que posibilita la estructura de lo humano, permitiendo que cada persona se muestre de distintos modos. A partir de esta ausencia de estructura nos estructuramos con relación a la cultura, la cual es el esquema estructurador más influyente. Por tanto, una particularidad de la naturaleza humana es su tendencia a la adaptación, de tal modo que el carácter esencial de la condición humana no es la libertad, sino el hecho de requerir adaptarse a algo. La adaptación requiere de aquello a lo cual habremos de adaptarnos, necesita de una estructura modeladora y moldeadora que es generada por la sociedad por mediación de la cultura.

La sociedad no es algo inherente al hombre, es más bien lo que le confiere su modo de ser, no su ser. Que el hombre requiera de una estructura para posibilitar su modo de ser, no supone que el hombre sea la estructura. Además, si la libertad es contingente a la estructura, entonces la libertad no es una esencia humana. Mainländer coincide en que ya no existe, o ya no puede pensarse, en alguna Unidad absoluta que lo une todo, como si la realidad fuese una serie de piezas homogéneas que se juntan por un mismo imán; al contrario, para el filósofo alemán, el fin de tal Unidad es generar distribución y diversidad. En su libro Filosofía de la Redención ${ }^{1}$ expone lo siguiente: "Ya no estamos más en Dios, porque la unidad simple se ha destruido y muerto. Por el contrario, estamos en un universo de la multiplicidad cuyos individuos se han unido a una sólida unidad colectiva" (Mainländer 2013, p. 50).

Visto así, la libertad no puede ser precedente. Lo que precede a la esencia, entendiendo la esencia como una especie de estructuración fundante, es la nada que permite el inicio de la estructuración misma. Ahora bien, como la nada no es el hombre sino lo que lo posee, entonces no puede ser la esencia construida, sino una esencia implícita. Por ello, aquello que propicia la indefinición del hombre es su propia nada.

La historia de la vida en el mundo nos muestra que el proceso evolutivo ha sido menos un proceso de libertad y más un proceso de adaptación; todo lo vivo ha estado sujeto a la realidad contingente, a las condiciones de la naturaleza. De ahí se desprende, a la manera de Darwin, que los seres que se mantienen vivos son los que mejor se adaptan y no los que son más libres. La adaptación es un proceso referido al modo de ser, a la tipificación del individuo en un espacio determinado. A su vez, no supone neutralización del sujeto ni deformación de su posibilidad de decidir; no obstante, sí implica que el conjunto de decisiones que el hombre realiza sean situadas a través de un vínculo con un entorno condicionante. El contexto orilla a la conciencia hacia una adaptación que no incluye en sí una categoría de libertad; tal como advierte Safranski (2013, p. 13): “Todo sería más sencillo si la conciencia fuera simplemente ser

1 En el presente texto se utilizó la antología de Sandra Baquedano (Santiago: FCE, 2013), quien seleccionó y editó algunos pasajes de la máxima obra de Mainländer. Asimismo, son recomendables la traducción completa de Die Philosophie der Erlösung, realizada por Manuel Pérez y editada por Carlos González (Madrid: Ediciones Xorki, 2014), así como la versión íntegra de la traducción de Baquedano, publicada de manera reciente (Santiago: FCE, 2021). 
consciente. Pero ésta se desgaja, se erige con libertad ante un horizonte de posibilidades. La conciencia puede trascender la realidad actual y descubrir una nada vertiginosa, o bien un Dios en el que todo alcanza su quietud".

Se podría objetar lo siguiente: si la condición humana es la adaptación, ¿cómo entender a los individuos desadaptados de una sociedad? ¿Son entes sin naturaleza? La respuesta no es tan simple. Para comenzar tendríamos que distinguir dos conceptos de adaptación: como seguimiento de estándares establecidos por la mayoría de miembros de un grupo y como la ubicación de un modo de ser dentro de las condiciones ambientales circundantes, sin la referencia directa a un consenso social. Si consideramos la segunda de las formas presentadas, aquellos a los que llamamos desadaptados en realidad no lo están.

La persona que opta por ejecutar conductas que están fuera de las normalmente elegidas por los miembros de su grupo no está realmente desadaptado por ello; de hecho, ha tomado esas decisiones en función de lo que lo rodea. Decidir ser diferente ya es una manera de haberse adaptado, pues está siendo diferente a algo que le es referente, de modo que su adaptación es real, aunque no de manera convencional. La adaptación es el ser-en-relación como posibilidad; en ese sentido, la apertura, la factibilidad de ser influidos y la maleabilidad constituyen en sí mismas la condición natural de lo humano.

En la sociedad, como masa maleable, cabe todo lo humanamente posible, incluso aquello que desde las estructuras hemos convenido que no sea aceptado. Pues bien, el hecho de no ser aceptado es ya una manera de adaptación, debido a que la no aceptación emana de un contexto o campo estructurado específico, con lo cual se rompe la opción de entender la adaptación como uniformidad.

La adaptación no supone igualdad ni linealidad en las maneras de ser humanos; simplemente se refiere a la opción de seguir o no seguir las cuestiones establecidas por un entorno ineludible. Tal entorno no es la esencia, pero solo en ese entorno es posible la idea de libertad delimitada.

Nuestra expectativa de ser libres, generada por la misma estructura, nos esclaviza; el camino de liberación se sujeta a la aceptación del vacío de la libertad. De este modo, la evolución muestra que las especies que se extinguieron no pudieron adaptarse de manera conveniente al entorno para lograr la sobrevivencia, pero sí se adaptaron de un modo que consecuentemente las hizo desaparecer. En los humanos, la adaptación es una implicación inevitable que no depende de la decisión más que para definir el contenido o el modo de la adaptación.

La opción por algo siempre será en la estructura, a manera de adaptación. Si hablamos de esencia, la tendencia hacia la adaptación precede a la libertad. Decidimos el modo en que nos adaptamos, más no el hecho de tender a la adaptación, lo cual sucede aun en el caso de una adaptación aparentemente desadaptada. ¿Es posible, en este contexto, liberarse de la libertad? Sí, en medida que uno se adapta a esa realidad de adaptación ineludible, lo cual elimina la angustia. ¿Por qué Sartre afirma que la angustia es el modo de la libertad? Porque propone ejercerla desde un modo exclusivo de adaptación que no incluye la versión adaptativa implícita en la aparente desadaptación; 
además, busca una esencialidad subjetiva de la libertad que al no ser, no llegar y no consumarse, no logra más que angustiarnos.

La angustia es posible en medida que creemos que en nuestras manos está nuestro porvenir. La angustia es proporcional a la suposición de ser hacedores directos del propio futuro. Pero eso solo es posible si no se ha entendido que somos una diminuta mancha cósmica en la inmensidad del Universo. No se trata de centrarse en sí para conocerse, no hay un conocimiento posible de uno mismo mientras estemos cerrados a reconocernos parte del mundo; el modo de conocer debe fundarse en nuestra categoría de seres-en-relación. Así, aun la negación de la estructura es una respuesta a la estructura. Cualquier propuesta de libertad que suponga desadaptación constituye una forma de adaptarse al contexto.

También vivimos adaptándonos a una condición fisiológica y biológica que nos pertenece. El hambre no es propia de nuestro ser sino de la condición de ser y de estar, de la propia relación con el cuerpo, del hecho de ser un cuerpo, de la constitución corpórea-humana. Uno puede comer o no comer, pero eso estará siempre en referencia al hambre. Cuando se opta por comer, uno se adapta de una manera directa a lo que exige su condición corporal y la relación con su cuerpo. Incluso no comer sería una adaptación consecuente al hambre, aunque no se tienda a la satisfacción de tal y pueda generarse daño.

Este posible daño en el organismo sería la consecuencia de la manera de adaptarse que cada uno muestra y representa una derivación implícita de nuestro seren-relación-con-el-cuerpo. Del mismo modo sucede con cualquier decisión tomada ante la interpelación de aquellos con los que uno se relaciona. Casarse, tener hijos, estudiar, viajar, vivir, enfrentar, discutir, matar o cualquier otra conducta, solo resulta posible debido a lo que está a nuestro alcance de manera circunscrita. Este contexto constituye la condición desde la cual al hombre le concierne adaptarse.

Cualquiera puede quedarse inmóvil y no optar, pero ese es ya un modo de adaptarse; se trata de una adaptación desde la pasividad o la inacción, pero eso ya supuso una conducta adaptativa que se derivó de una decisión, aunque tal no sea totalmente libre. La libertad, en este caso, es solo un residuo que nuestra percepción presenta, a la manera de una maniatada voluntad en las decisiones. Pero como la misma voluntad, entendida como facultad apetitiva, está siempre situada y condicionada, la libertad termina asfixiada por una constante dialéctica entre el entorno y nuestra percepción, no se trata de una libertad a manera de esencia o de una libertad absoluta como la pretensión humana podría desear.

Podemos creer que somos libres, pero no lo sabemos realmente. Según Sartre (2006, p. 123), "creer es saber que se cree y saber que se cree es no saber ya"; análogamente, saber que uno se miente no es ya una mentira, pues al saberlo la mentira queda rota. El que tiene fe no sabe que tiene fe, cree que sabe aquello de lo cual solo tiene fe. Saber que no somos rompe nuestro afán de ser, del mismo modo que ser consciente de la inconsciencia hace que esto disminuya la inconsciencia.

La conciencia es controlar, pero no hay manera de controlar sin tener control; en otras palabras: "no podría disimularme que creo para no creer y que no creo para 
creer" (Sartre 2006, p. 123). Siguiendo la misma línea de Sartre (2006, p. 124), si una persona necesita creerse inteligente es porque cree que es ingenua, pero realmente no es ni una ni otra cosa. Todo es creencia y, si toda creencia es falsa, creer ser libre es falsedad. Vivimos en la época del desconocimiento del propio defecto, de la ausencia de autocrítica. No hay forma de saberse en el error si no hay admisión de una definición del mismo; esta idea, de acuerdo con Sloterdijk (2003, p. 39), se clarifica en la siguiente expresión: "El cínico moderno es un integrado antisocial que rivaliza con cualquier hippy en la subliminal carencia de ilusiones. Ni siquiera a él mismo su perversa y clara mirada se le manifiesta como un defecto personal o como un capricho amoral del que debe responsabilizarse en privado".

No hay forma de estar vivo sin adaptarse a la estructura. En Occidente hemos forjado nuestra historia desde la estructura del ser. Es momento de adaptarnos a la nada, a la estructura que desestructura. Cabe resaltar que el problema directo nunca ha sido el ser, sino entenderlo absoluto y desligado de la nada. Es necesario adaptarnos a nuestra estructura íntima, la cual es clara evidencia de la dialéctica del ser con la nada. Tal dialéctica supone el cambio ineludible.

\section{El yo, el cambio ineludible y la vacuidad}

Es posible que uno de los miedos hacia la opción por la nada sea la fortificada centralización en el ser. Sin embargo, el cambio es una cuestión ineludible que pone en evidencia la presencia de la nada. Estamos en modificación a cada instante, aun sin decidirlo, lo cual es producto de la dialéctica del ser con la nada. Morimos a cada segundo, cada vez hay más muerte en nosotros (o una vida diferente) debido a que nuestra existencia no es la misma a cada instante, nos cambiamos, nos modificamos, somos otros. Esto sucede tan intempestivamente que no nos damos cuenta; suponemos una continuidad de la vida cuando, en realidad, lo único que se reproduce continuamente es un ser que es y muere incesantemente.

Así como no notamos que estamos en movimiento y que incluso sobre nuestros pies suceden cambios derivados de la gravitación de la tierra alrededor del sol, no captamos nuestra continua muerte. La inmutabilidad es únicamente ilusión. La continuidad de la vida también lo es, se trata de un juego de nuestra propia conciencia.

Podría objetarse que siempre hemos sido los mismos debido a que nuestro cuerpo nos ha acompañado durante toda nuestra vida. Pues bien, ni siquiera nuestras células actuales son las mismas que hace un año. Nuestras células mueren, se reproducen, cambian. Nuestro cuerpo no es necesariamente el mismo, ni siquiera superficialmente. ¿Podemos decir lo mismo de nuestros pensamientos y modos de entender el mundo? Desde luego, a menos que alguien suponga que hoy piensa igual a como lo hacía en su infancia. ¿Puede la supuesta libertad esencial evitar la modificación celular? De ninguna manera, así como tampoco es posible evitar las múltiples condicionantes que el cuerpo nos infringe. Incluso los impulsos sexuales son una consecuencia derivada de tener-ser un cuerpo. Aunque es sabido que algunos afirman que han controlado todos 
sus impulsos sexuales, el hecho mismo de que necesiten "controlarlos" es evidencia de su imposibilidad de optar por una situación tal que suponga no tener nada que controlar.

Por todo lo anterior, los cambios son propios debido a que somos. Si la libertad es una ilusión, comencemos por liberarnos de tal idea. Es necesario derribar el miedo de asumir la nada, de enfatizar la imposibilidad de ser entes inmutables. Si bien no podemos evadir la inoperancia del deseo prepotente de tenerlo todo bajo control, cambiamos incluso sin voluntad.

La imposibilidad de que nuestra conciencia sea consciente de todos los cambios es lo que nos genera la fantasía de que seguimos siendo los mismos. ¿Alguna vez hemos sido conscientes de cada respiración realizada durante un día entero? ¿Estamos seguros de que captamos todo lo que está a nuestro alrededor, de que escuchamos todos los sonidos y vemos todas las imágenes frente a nosotros? ¿Captamos la sangre en nuestras venas, el corazón latir, las neuronas funcionar, la pupila dilatarse, el pelo crecer o nuestra digestión? La conciencia siempre es parcial, no captamos más que breves porciones del todo. Tales espasmos de conciencia están vinculados a la asociación de imágenes que nos recuerdan cómo éramos en el pasado.

Por la inconsistencia suprema de nuestra conciencia suponemos la continuidad, pero no captamos las múltiples e interminables rupturas de nuestro propio ser consigo mismo. En ese panorama, el yo es la figuración más sofisticada de la conciencia. Si la existencia es la esencia y ésta es modificable incesantemente, entonces el yo, aquello que supuestamente es a cada instante, no tiene más vida que el instante presente que se desvanece mientras es, que siendo desaparece, que en su ser le va su ser. Mientras no podamos seguir siendo los mismos una vez que el cambio sucede, entonces tampoco somos lo que ahora creemos ser porque antes fuimos otros.

El yo no es la conciencia, sino su producto. La vida práctica y la urgencia de la de las cosas cotidianas nos ha conducido a perder la noción de la vacuidad; no obstante, lejos de que esto constituya un beneficio nos ha orillado a ser controlados por las ideologías, tal como advirtió Adorno (2001, p. 39): "El sentido práctico entre los hombres, que elimina todo ornamento ideológico entre ellos, ha terminado por convertirse en ideología para tratar a los hombres como cosas".

Por ello, la principal categoría de la naturaleza humana es la tendencia a la adaptación; si la esencia se concibe como la naturaleza humana, entonces tal naturaleza se modifica de acuerdo a aquello a lo que se ha de adaptar. Los contenidos de nuestra adaptación se alternan y nos adaptamos a las cosas que están fuera de nosotros. Nuestro modo de existir se sostiene en ello, somos seres cuya existencia está condenada a la adaptación. Esto contradice la idea de que existe un espíritu inmutable que provoca que nosotros, al ser forjados por él, tampoco somos mutables. De hecho, la relación directa y pura con un espíritu absoluto es improbable debido a que, en su categoría de absoluto, no podría estar relacionado con lo humano por su diferencia ontológica. Tampoco es posible volvernos uno con Él, debido a que tal espíritu absoluto está forzosamente dotado de inmutabilidad en función de su carácter absoluto, por lo cual no admite ninguna suma; lo absoluto no puede tener adiciones. La suposición de una vida tras la muerte, en la cual dos entidades centradas en el ser se fusionan resulta 
ser una quimera desde este orden de ideas. No hay inmutabilidad en ningún espíritu absoluto centrado en el ser y tampoco hay inmutabilidad en nuestro ser. No obstante, sí la hay inmutabilidad en la nada absoluta.

El cambio está siempre, pero tales cambios se pierden a nuestra percepción debido a las secuencias constantes de nuestra conciencia. En la conciencia se presenta el presente, el futuro y el pasado; en la conciencia es el acto y la potencia, la existencia y la esencia. Sin embargo, en lo estrictamente fenoménico solo el presente es, solo el acto es y, por tanto, solo la existencia es.

Ahora bien, como lo ontológico, el concepto y su acuñación, es también un producto de la subjetividad, un aparato de la propia conciencia, no hay manera de entender lo ontológico fuera de la conciencia. No es posible entender al ser sin contingencia. Solo lo absoluto sería no contingente, pero no cabría su posibilidad en el mundo de lo humanamente explicable. La nada que vemos, al no verla, es una percepción de lo no percibido; la imposibilidad de su percepción nos permite percibirla. No hay modo humano de escapar de la nada, lo que sí podemos es convertirnos en ella. En ese caso, solo podemos escapar de la conciencia de ser poseídos por la nada, pero nunca de la nada como tal.

Necesitamos la conciencia del pasado para creer el mito del yo, a menos que podamos hacer frente a la conciencia de su nulidad. El pasado solo existe en medida que lo ubicamos en la conciencia. Ahora bien, el presente también es captado exclusivamente debido a la conciencia. El presente y el pasado son una vivencia sensible solo si se es consciente de ambos.

Por más veces que uno despierte o duerma, por más sueños o no que se tengan, de cualquier modo no hay manera de salir de la burbuja de la fantasía mental. La vida es una alucinación prolongada producida por la conciencia. Es por esto que la conciencia, que es lo más complejo de cada humano, es conciencia también del yo; tal yo es una ficción en la conciencia.

La conciencia define lo que es y no es para nosotros, incluidos los conceptos de la nada. El hecho de captar o no captar la nada no interfiere en su existencia; es más nada de sí misma para quien no la capte. Resulta evidente que hay cosas que aún permanecen en la nada para el ser humano y seguramente habrá aspectos que jamás serán conocidos. Habrá conocimientos que serán una ausencia perpetua por no lograrse un descubrimiento de los mismos. La nada supera a la conciencia, la ficción está por encima de ella. Nuestra angustia ante la nada es derivación de la conciencia de nuestro límite, no solo de la propia conciencia, sino del conjunto de conciencias de toda la historia de la humanidad.

\section{Conclusión}

Podemos decidir sobre la liberación de las estructuras, no sobre la existencia de las mismas en el contexto o en el mundo de los que nos acompañan en la Tierra. Contemplar ese límite es siempre una opción individual de adaptación a la estructura desde la 
desestructura, es la consecuente afirmación de la nada. Somos entes que pueden asumir la nada, incluso desde su estructura.

Es tiempo de volver a la nada, de considerar que ha estado siempre, que ha permanecido con nosotros y que somos en parte ella misma. La nada puede ser la pauta necesaria para nuestra liberación. No necesitamos más respuestas desde el ser, centradas unívocamente en la estructura asfixiante de nuestras verdades. Demos una oportunidad a la nada para vitalizar nuestro ser, es oportuno contemplar la Nada antes de que la seamos definitivamente.

\section{Referencias bibliográficas}

Adorno, T. (2001), Minima moralia. Madrid: Taurus.

Bourdieu, P. (2005), Invitación a la sociología reflexiva. Buenos Aires: Siglo XXI.

Cioran, E. (2009), En las cimas de la desesperación. México: Tusquets.

Mainländer, P. (2013), Filosofía de la redención. Antología, ed. por S. Baquedano. Santiago: FCE.

Safranski, R. (2013), El mal o el drama de la libertad. México: Tusquets.

Sartre, J. P. (2006), El ser y la Nada. Buenos Aires: Losada.

Sloterdijk, P. (2003), Critica de la razón cínica. Madrid: Siruela. 